\title{
SÓ PASSANDO POR CIMA DO MEU CADÁVER: UMA ANÁLISE DO DISCURSO DE EDUARDO CUNHA SOBRE A LEGALIZAÇÃO DO ABORTO
}

\author{
Camilla Ramalho Duarte ${ }^{\mathrm{i}}$ \\ Rosane Santos Mauro Monnerat ${ }^{\text {ii }}$
}

Resumo: A legalização do aborto é tema tabu na sociedade brasileira, ainda mais para o ex-presidente da Câmara dos Deputados, Eduardo Cunha. Pensando, então, na dificuldade de separar política e religião é que este trabalho se justifica, pois tem como objetivo analisar as declarações pró-criminalização do aborto, feitas pelo político. Para tal, tem-se como ponto de partida a Teoria Semiolinguística de Análise do Discurso, cunhada por Patrick Charaudeau, no que tange aos sujeitos do ato de linguagem e suas identidades, que determinarão "quem fala com quem". Recorrerse-á, ainda, à noção de ethos, recuperada da tradição aristotélica, que tem a ver com a construção da imagem de si que o sujeito faz discursivamente. Assim, pode-se pensar que as declarações do ex-congressista se tornaram mote para uma discussão relevante sobre a legalização do aborto, mostrando o quanto o discurso político influencia as decisões tomadas pelo Congresso e a vida da população brasileira.

Palavras-chave: Aborto. Política. Semiolinguística. Eduardo Cunha.

\begin{abstract}
The legalization of abortion is a taboo subject in Brazilian society, especially for the President of the Chamber of Deputies, Eduardo Cunha. The difficulties in separating religion and politics justifies this work, which aims at analyzing the procriminalization of abortion declarations uttered by the mentioned politician. In order to do so, we draw both on the Semiolinguistic Theory of Discourse Analysis proposed by Patrick Charaudeau in terms of the concept of subjects in the linguistic act and his identities, which determine "who talks to whom", and on the notion of ethos, brought from the Aristotelian tradition, to understand the discursive construction of the subject's self-image. In this way, it is possible to think that the ex-Congress member's speech became the motto for a relevant discussion about abortion and its legalization, showing how much the political speech influences the decisions made by the Brazilian institutions and therefore the Brazilian people.
\end{abstract}

Keywords: Abortion. Politics. Semilinguistic. Eduardo Cunha.

\footnotetext{
'Doutoranda em Estudos de Linguagem pela Universidade Federal Fluminense (UFF), Brasil. E-mail: camillarduarte22@hotmail.com.

ii Professora Titular da Universidade Federal Fluminense (UFF), Brasil.

E-mail: rosanemonnerat@id.uff.br
} 
EID\&A - Revista Eletrônica de Estudos Integrados em Discurso e Argumentação, Ilhéus, n. 14, jul/dez.2017.

\section{Introdução}

A legalização (ou não) do aborto é uma questão polêmica, que traz à baila opiniões divergentes no cenário sócio-político do país. Eduardo Cunha, por sua orientação religiosa, faz parte do grupo que se posiciona contra essa prática.

Neste trabalho, propõe-se analisar um fragmento do discurso do expresidente da Câmara dos Deputados do Brasil, Eduardo Cunha - destituído do cargo e preso, acusado de corrupção em uma das fases da Operação LavaJato -, no que tange à legalização do aborto, que ainda é um tema tabu dentro da sociedade brasileira. Na realidade, embora o número de abortos tenha diminuído em grande parte dos países onde houve sua legalização, os argumentos de cunho religioso, principalmente daqueles que se autointitulam pró-vida, parecem ecoar em uma população que é, também ela, religiosa e que considera o feto como sendo uma vida que não pode ser morta.

Em verdade, parece haver uma preocupação excessiva com relação ao feto; contudo, não há uma preocupação com as mulheres que continuam recorrendo às clínicas clandestinas para realizar abortos. Ou seja, a proibição em nada diminui o número de procedimentos, o que só acontece quando há políticas públicas de esclarecimento no que se refere aos métodos contraceptivos - ainda que esses falhem - e à própria realização do aborto.

Vale lembrar, ainda, que mulheres pertencentes a uma classe social mais abastada, geralmente brancas e escolarizadas, conseguem pagar o preço exorbitante que cobram as clínicas, realizando abortos sem maiores transtornos, o que não acontece com as mulheres negras e pobres que precisam recorrer a clínicas clandestinas, onde o procedimento é feito em condições de higiene precárias. No Brasil, parece existir, então, a criminalização não só do aborto, como também da pobreza; afinal, a maioria das mulheres que morre durante um aborto é negra, pobre e periférica.

Para que todo esse discurso pró-criminalização do aborto seja analisado, precisar-se-á recorrer a algumas noções trazidas pela Teoria Semiolinguística de Análise do Discurso, cunhada por Patrick Charaudeau, a partir da década de 1980 , no que diz respeito ao conceito de sujeito, posto que todo o discurso político do ex-deputado é permeado por sua identidade social, que determinará "quem fala com quem" em termos de relações de força, presentes em todo ato de linguagem. 
EID\&A - Revista Eletrônica de Estudos Integrados em Discurso e Argumentação, Ilhéus, n. 14, jul/dez.2017.

As relações de força fazem emergir a questão do "direito à palavra", ou seja, do problema que se coloca a qualquer sujeito - que deseja falar - de ser reconhecido pelo outro como digno de ser escutado. É necessário, portanto, que o sujeito falante tenha um mínimo de legitimidade, a qual depende da posição que esse sujeito ocupa (real ou imaginariamente) nos domínios do poder e do saber.

O domínio do saber é o espaço em que circulam os discursos de verdade e de crença que são próprios a grupos ou comunidades socioculturais. Esses discursos têm como sujeito espécies de Vox populi fragmentadas, em relação às quais será julgado o sujeito falante. O domínio do poder, por sua vez, é o espaço em que as condições sócio-institucionais podem ser ligadas aos parceiros, conferindo-lhes posição social e autoridade (CHARAUDEAU, 1994).

É, portanto, a posição que ocupava o ex-deputado, dentro do cenário político brasileiro, que lhe dava o poder da palavra para que ele se mostrasse radicalmente contra o aborto, tentando captar seus destinatários para o que dizia, pois era necessário que seu discurso inspirasse legitimidade, já que, para ele, já era passível de credibilidade.

Assim, é possível estabelecer que o sujeito comunicante, ser social, dará voz a um sujeito enunciador, ser discursivo, que terá como meta persuadir seus sujeitos destinatários para que esses adiram à sua posição ideológica, engendrando, nos sujeitos interpretantes, uma necessidade de tomar, também eles, a mesma posição que tem o ex-congressista. Contudo, pode ser que o sujeito interpretante e o destinatário sejam assimétricos, o que comprometerá a adesão ao discurso do parlamentar, haja vista que o sujeito real, indivíduo do mundo extralinguístico, não concordará com as opiniões de Cunha e, por esse motivo, mostrar-se-á a favor da legalização do aborto.

Para que as análises e discussões acima formuladas aconteçam, é necessário expandir os conceitos mencionados, aprofundando algumas noções teóricas.

\section{Eixos teóricos}

Em primeiro lugar, torna-se imprescindível ampliar as noções de sujeito, de acordo com a Teoria Semiolinguística de Análise do Discurso, deixando claro que tais sujeitos não se assujeitam às ideologias dominantes, posto que 
EID\&A - Revista Eletrônica de Estudos Integrados em Discurso e Argumentação, Ilhéus, n. 14, jul/dez.2017.

podem ir contra elas, transformando-as e subvertendo-as, uma vez que são dotados de intencionalidade.

De acordo com Charaudeau, todo texto está inscrito em um circuito interno, da mesma forma que também está inscrito em um circuito externo. Entende-se por circuito interno os aspectos efetivamente linguísticos de um texto, em que não se considera a situação comunicativa em que está inscrito, assim como são postas de lado suas condições de produção e sua incursão sócio-histórica, o que diz respeito ao circuito externo do texto. Desse modo, todos os textos, de acordo com essa teoria, devem ser analisados, em primeiro lugar, por meio de seu viés linguístico, mas também devem ser levadas em consideração as suas condições de produção externas, que, muitas vezes, determinam a maneira como se deve compreendê-los e interpretá-los.

$\mathrm{Na}$ presente teoria, os sujeitos têm, portanto, um papel de destaque, porque são os produtores e receptores dos discursos propagados, como é o caso do de Cunha. Eles, os sujeitos, subdividem-se, por sua vez, em sociais e discursivos: aqueles são seres que existem no mundo extralinguístico, já que são reais e têm identidade psicossocial, e estes existem apenas no universo da palavra, haja vista que se constroem no e pelo discurso. Desse modo, constata-se que os sujeitos possuem duas identidades concomitantes: uma social e outra discursiva, sendo que:

[...] a identidade social necessita ser reiterada, reforçada, recriada, ou, ao contrário, ocultada pelo comportamento linguageiro do sujeito falante, e a identidade discursiva, para se construir, necessita de uma base de identidade social (CHARAUDEAU, 2009a, p. 313-314).

No circuito externo ao texto, há dois sujeitos, um responsável pela instância da produção, chamado comunicante, e outro, pela da recepção, conhecido como interpretante; os dois são seres do mundo real. Dentro do circuito interno do texto, por sua vez, há, também, dois sujeitos: o responsável pela instância da produção, o eu enunciador, e outro, pela da recepção, o tu destinatário. Dessa maneira, percebe-se que o eu comunicante dá voz ao eu enunciador dentro do discurso, da mesma maneira que o tu interpretante dá voz a um tu destinatário.

A essa altura, é importante esclarecer que os sujeitos sociais idealizam os sujeitos discursivos: as idealizações que ocorrem no circuito externo do texto podem, ou não, se concretizar dentro do circuito interno, dentro do próprio 
EID\&A - Revista Eletrônica de Estudos Integrados em Discurso e Argumentação, Ilhéus, n. 14, jul/dez.2017.

discurso. Logo, observa-se que o eu comunicante idealiza o tu destinatário ao qual se dirige, algo que sucede de maneira semelhante com o tu interpretante, que também idealiza o eu enunciador com quem fala. Entretanto, nem sempre o eu comunicante coincidirá com o eu enunciador, do mesmo modo que o tu interpretante nem sempre será simétrico ao tu destinatário de um discurso.

A identidade social precisa, dessa forma, ser reconhecida e legitimada pelo outro, haja vista que tal reconhecimento, como vimos, é o que confere a um indivíduo seu "direito à palavra" (CHARAUDEAU, 2009a, p. 3). Em outros termos, é imprescindível que alguém lhe diga que está autorizado a atuar da maneira como atua, o que depende, obviamente, do local de onde fala e da situação de comunicação da qual faz parte. Da mesma forma, quando um indivíduo usa o discurso de maneira inapropriada aos olhos do outro, seu direito de legitimidade é posto em xeque, uma vez que não seria permitido falar assim.

A legitimidade, todavia, não é suficiente para fundamentar o direito à fala e isso porque pode simplesmente ser ignorada ou contestada pelo outro. É necessário, portanto, que o sujeito falante adquira, igualmente, credibilidade, a qual depende do "saber fazer" do sujeito nos quatro tipos de atividade da linguagem: informar ("fazer saber"), persuadir ("fazer crer"), seduzir ("fazer prazer") e incitar ("fazer fazer").

É exatamente a partir do "saber fazer" que o sujeito constrói as diferentes máscaras de sua identidade discursiva. Segundo Charaudeau:

[...] a identidade discursiva se constrói com base nos modos de tomada da palavra, na organização enunciativa do discurso e na manipulação dos imaginários sociodiscursivos. Ao contrário da identidade social, a identidade discursiva é sempre algo "a construir - em construção". Resulta de escolhas do sujeito, mas leva em conta, evidentemente, os fatores constituintes da identidade social (CHARAUDEAU, 2009a, p. 318).

A identidade discursiva do falante se constrói, desse modo, com a finalidade de responder à questão: "Estou aqui para falar como?" e é por essa razão que depende das estratégias de credibilidade e de captação. A primeira está relacionada à necessidade que o sujeito falante tem de fazer com que se acredite naquilo que ele diz, tanto na verdade do discurso, quanto na sua sinceridade. Para que o levem a sério e para fazer seu discurso passível de credibilidade, ele pode adotar diferentes atitudes discursivas, como, por exemplo, a da neutralidade, em que apaga, no seu discurso, qualquer resquício de juízo de valor; a do distanciamento, na qual tende a adotar uma 
EID\&A - Revista Eletrônica de Estudos Integrados em Discurso e Argumentação, Ilhéus, n. 14, jul/dez.2017.

atitude fria para analisar, sem paixão, o discurso em questão; e a do engajamento, na qual opta por tomar uma posição ao escolher quais argumentos usará a fim de persuadir ou cooptar seu interlocutor.

Nesse sentido, o processo de captação do outro, dentro da troca comunicativa, consiste, como o próprio nome sugere, em captar o destinatário para aquilo que está sendo dito pelo sujeito falante. Em outras palavras, a captação nada mais é do que convencer o outro a adotar o discurso trazido por quem detém a palavra. Trata-se, portanto, de fazer com que o sujeito interpretante partilhe do discurso, das ideias e dos ideais defendidos por quem fala, evitando uma possível segregação entre ambos. As estratégias utilizadas pelo eu-falante para convencer/seduzir seu interlocutor são elencadas quando aquele não está em uma posição de autoridade em relação a este, já que, se estivesse, uma ordem bastaria para que o processo de captação se realizasse, sem que houvesse nenhum empecilho.

Charaudeau (2009b) chama a atenção para o fato de que, dentro da esfera política, há relações de força simbólicas, que são engendradas por meio da conquista e do manejo de um poder que não pode ser exercido sem que exista uma legitimidade adquirida e atribuída. Contudo, isso não é suficiente, uma vez que o sujeito político precisa parecer crível e persuadir o maior número de indivíduos, a fim de que compartilhem os valores que traz. A política, então, assume uma dupla perspectiva na construção do pensamento político que deverá representar um sistema de valores idealizado e, também, manipular a opinião pública para estabelecer, com ela, um consenso.

O sujeito falante, por sua vez, pode, ainda, adotar atitudes discursivas diferentes das já mencionadas com relação ao seu interlocutor: pode ser polêmico, quando tenta antecipar as possíveis objeções do outro, com o objetivo de eliminá-las; pode ser sedutor, quando propõe ao seu interlocutor um processo de identificação ou rejeição, por meio de sua atividade linguageira, e pode, também, adotar a atitude de dramatização, quando tenta fazer com que seu interlocutor sinta certas emoções para convencê-lo daquilo que quer.

Em quaisquer dessas situações, haverá sempre projeções do ethos do sujeito comunicante/enunciador, já que o ethos é um aspecto inseparável da enunciação. De fato, enquanto a tradição aristotélica define ethos como uma projeção intencional das qualificações morais do locutor por meio de seu discurso, com evidência em sua capacidade de transmitir credibilidade pela 
EID\&A - Revista Eletrônica de Estudos Integrados em Discurso e Argumentação, Ilhéus, n. 14, jul/dez.2017.

persuasão do alocutário, os estudos discursivos atuais partem da ideia relativamente consensual de que:

[...] toda fala implica a construção de uma imagem de si. Para tanto, não é necessário que o locutor faça seu retrato, detalhe suas qualidades nem mesmo que fale explicitamente de si próprio. Seu estilo, suas competências de linguagem e enciclopédicas, suas crenças implícitas bastam para dar uma representação de sua pessoa. Deliberadamente ou não, o locutor efetua assim no seu discurso uma apresentação de si (AMOSSY, 2005, p. 9).

Charaudeau, por sua vez, afirma que há um ethos condizente com cada identidade que o sujeito assume: há um ethos pré-discursivo, que existe antes mesmo de o sujeito enunciador empreender seu discurso, além de corresponder à imagem que tal sujeito traz enquanto ser social e empírico. Por outro lado, há um ethos que só é ativado por vias discursivas, ou seja, por meio do próprio ato de linguagem. $O$ ethos, [então] relaciona-se ao cruzamento de olhares: olhar do outro sobre aquele que fala, olhar daquele que fala sobre a maneira como pensa que o outro o vê (CHARAUDEAU, 2013, p. 115).

O ethos, então, para o teórico francês, não é totalmente voluntário nem consciente e não precisa coincidir, necessariamente, com aquilo que o destinatário percebe; afinal, é, antes de tudo, uma imagem construída tanto pelo sujeito enunciador quanto pelo seu destinatário, apesar de haver um desejo de que o sujeito se mostre tal qual ele é e que ele não faça uso de máscaras.

Já Maingueneau (2005) chama a atenção para a natureza do enunciador, o qual considera como uma instância subjetiva encarnada que exerce o papel de fiador (p.72). A subjetividade, vale dizer, não corresponde ao ethos; porém, as marcas de subjetividade, ou seja, as escolhas formais e o estilo que denunciam a intervenção do enunciador é que se configuram como a matéria de construção do ethos. Por essas escolhas, o enunciador, intencionalmente, ou não, mostra-se em seu discurso.

Com foco nas referidas escolhas, procuraremos desvelar as marcas enunciativas que subjazem ao discurso de Eduardo Cunha.

2. Desvendando as estratégias de credibilidade e legitimidade do discurso de Eduardo Cunha

Iniciaremos, neste ponto do trabalho, a articulação dos eixos teóricos, aqui assumidos, com o discurso de Cunha, objetivando demonstrar as 
EID\&A - Revista Eletrônica de Estudos Integrados em Discurso e Argumentação, Ilhéus, n. 14, jul/dez.2017.

estratégias linguístico-discursivas elencadas pelo ex-parlamentar, a fim de cooptar seu destinatário para o que diz.

Pensando apenas no trecho do discurso relatado, no título da notícia, a saber, Eduardo Cunha sobre aborto: 'vai ter que passar por cima do meu cadáver para votar', pode-se dizer que, nesse fragmento, há quatro sujeitos responsáveis pelo ato de linguagem, sendo dois pertencentes à instância da produção e dois, à da recepção. Os sujeitos que figuram na produção do enunciado são o sujeito comunicante, ser de carne e osso, que vive no mundo, o próprio ex-deputado federal Eduardo Cunha, que dá voz e vez a um sujeito enunciador, o qual só existe no e pelo discurso. Na realidade, esse sujeito enunciador faz vir à tona, discursivamente, as opiniões, ideologias e ideias do próprio ex-deputado, que se mostra contrário à regulamentação do aborto.

Por outro lado, o sujeito enunciador dirige-se, dentro do circuito interno do ato de linguagem, a um sujeito destinatário, ao qual é dada voz por um sujeito interpretante que são, por exemplo, os leitores reais que leem essa notícia. $O$ sujeito destinatário, por sua vez, são aqueles sujeitos virtuais que só existem dentro da cena enunciativa e dialogam com o produtor dos enunciados.

Como se sabe, todo ato de linguagem visa à persuasão do outro, o que não seria diferente com o discurso do ex-presidente da Câmara dos Deputados. Logo, o sujeito enunciador quer captar seu destinatário para o que diz, tornando-o cúmplice do discurso pró-criminalização do aborto, fazendo com que ele adira à sua posição de sujeito enunciador e também se mostre favorável à criminalização do aborto.

Em verdade, o eu-falante deu a si mesmo legitimidade para dizer o que diz, já que ocupava, à época, um cargo de prestígio dentro do cenário político brasileiro, o que tornava possível que ele se posicionasse dessa maneira nos principais veículos de comunicação do país. Tal posição de autoridade que o sujeito confere a si próprio faz com que ele empreenda relações de força contra aqueles que se opõem ao discurso da criminalização do aborto e que usam argumentos que nada têm a ver com a religião, ao contrário do que faz Cunha.

Ainda que o discurso do ex-parlamentar pareça passível de credibilidade para ele mesmo, torna-se necessário que os sujeitos destinatários legitimem o referido discurso, uma vez que, sozinho, não seria capaz de levantar uma bandeira tão importante como essa, posto que se trata do direito das 
EID\&A - Revista Eletrônica de Estudos Integrados em Discurso e Argumentação, Ilhéus, n. 14, jul/dez.2017.

mulheres em relação ao seu próprio corpo. Assim sendo, é imprescindível que os destinatários sejam convencidos a apoiar a continuidade da criminalização do aborto, caso contrário, o discurso perderá força e terá muito mais indivíduos contrários do que a favor daquilo que é dito.

Desse modo, é possível apreender que o sujeito comunicante, assim como o enunciador, idealiza o público-alvo de seus discursos, o que pode coincidir, ou não, com a realidade. Explica-se: pode ser que o sujeito, idealizado pelo produtor dos discursos, corresponda a esse perfil idealizado, no entanto, pode ser que esse sujeito se apresente como sendo assimétrico àquele idealizado, rejeitando o discurso pró-vida do deputado, colocando-se como adversário do que está sendo dito.

É justamente nessa assimetria que se inscreveu a chamada Primavera das Mulheres, que foi uma manifestação feminista, organizada em várias cidades do Brasil, em que elas se colocaram contra uma política de retrocessos, encabeçada por Cunha, que empreendeu um projeto de lei que diminuiria os direitos das mulheres sobre seu próprio corpo, já que propunha dificultar o atendimento às vítimas de estupro, pelo SUS, e o acesso à pílula do dia seguinte por essas mesmas mulheres.

Portanto, ainda que o discurso de Cunha encontre eco, ou seja, credibilidade em alguns de seus destinatários, há quem se posicione contra ele, não se deixando captar por um discurso de cunho religioso e não científico, haja vista que todos os métodos contraceptivos falham, e o aborto diz respeito, justamente, a uma tentativa de dar mais autonomia às mulheres para tomar suas próprias decisões, principalmente, no que tange aos seus próprios corpos.

Torna-se fundamental ressaltar que as estratégias, empreendidas pelo sujeito enunciador, no que diz respeito à persuasão e à captação do destinatário, são adotadas, visto que esse sujeito não se encontra em posição de superioridade e, consequentemente, de autoridade, ainda que fosse, em outro momento, presidente da Câmara dos Deputados, pois, se isso acontecesse, seria necessário apenas dar uma ordem para que todos concordassem ou fingissem concordar com o que é dito por ele.

Por outro lado, a subjetivação, que todo político busca, já que, obviamente, tem por objetivo persuadir seu destinatário daquilo que diz, aumenta ainda mais quando ele, o político, consegue adotar o mesmo ponto de vista do cidadão comum, o qual, por sua vez, poderá crer que a opinião 
política, trazida por um de seus representantes, nesse caso, o ex-parlamentar do PMDB, equivale a um posicionamento surgido do fundo de sua história pessoal. Explica-se: é como se fosse necessário que o sujeito destinatário acreditasse que a ideia de considerar o aborto um crime tivesse surgido de sua própria cabeça e não que fosse uma ideologia construída por séculos de dominação do patriarcado e apenas reproduzida pelo ex-deputado.

Em verdade, o sujeito enunciador de Cunha adota uma atitude de engajamento quando tenta persuadir o outro a aceitar aquilo que diz, fazendo com que ele, o destinatário, seja implicado em uma tomada de posição, de preferência, favorável à visão ideológica do enunciador, já que é esse o objetivo primeiro do eu falante: convencer seu destinatário a concordar com aquilo que diz.

Vale dizer que essa é a postura prototípica dos políticos: precisam convencer e, a partir dessa premissa, desenvolvem figuras identitárias reagrupadas em torno de duas grandes categorias de ethos: o ethos de credibilidade e o ethos de identificação.

Considerando-se que a identidade do sujeito passa por representações circulantes na sociedade - os imaginários sociodiscursivos - pode-se dizer que Cunha tem uma opinião sobre o que julga correto e pretende passar isso aos seus ouvintes, já que se apresenta com um ethos de credibilidade (condições de sinceridade, performance e eficácia), que o obrigariam a provar que tem meios para executar o que promete, com resultados positivos, o que o leva, ainda, a construir para si os ethe de sério, virtuoso e competente. Por outro lado, ao tentar convencer o auditório, chama também a si ethe de identificação, orientados para o outro, ou seja, os cidadãos (não apenas da bancada evangélica) para que se solidarizem com o que diz e aceitem seu ponto de vista (CHARAUDEAU, 2013).

As escolhas lexicais contribuem para a criação de uma atmosfera que se pretende austera, vigorosa e verdadeira. $O$ enunciado hiperbólico - vai ter que passar por cima do meu cadáver pra votar - transforma-se em argumento na defesa da tese que propõe: a criminalização do aborto.

\section{Considerações finais}

O posicionamento assumido pelo ex-deputado federal Eduardo Cunha, no que diz respeito à legalização do aborto, pode ser considerado polêmico, 
EID\&A - Revista Eletrônica de Estudos Integrados em Discurso e Argumentação, Ilhéus, n. 14, jul/dez.2017.

uma vez que o tema é tabu dentro de nossa sociedade patriarcal. Tal caráter polêmico fica ainda mais reforçado por conta das escolhas linguísticas que faz o sujeito comunicante para dar voz ao sujeito enunciador: o uso de uma expressão cristalizada que carrega consigo, como dito, um viés hiperbólico: trata-se da máxima só passando por cima do meu cadáver.

$\mathrm{Na}$ realidade, ainda que o sujeito se achasse digno de legitimidade e que os mais de 200 mil votos que recebeu, nas eleições de 2014, Ihe dessem credibilidade, o discurso de Cunha encontrou resistência nas ruas, já que muitos de seus ouvintes acreditam que o fato de o Estado ser laico impede a propagação de discursos de ordem religiosa, que dialogam com dogmas também religiosos, especialmente, das igrejas denominadas neopentecostais.

Assim, a imagem que o sujeito enunciador construiu para si dentro do discurso, nesse caso, um ethos de credibilidade e de identificação, parece ter trazido consigo rachaduras, haja vista que muitos dos destinatários, principalmente, mulheres feministas, tornaram-se adversários, produzindo, inclusive, outros discursos que rechaçaram o que foi dito pelo político em questão.

Para finalizar, é possível sustentar que a veiculação do referido enunciado estabelece um diálogo com a ideia de que o sujeito político precisa executar aquilo que o enunciador prometeu em suas campanhas para angariar votos, ainda que tais decisões não sejam de sua alçada ou que se choquem com a maneira como o Estado deve agir enquanto regulador das práticassociais, nesse caso, sem influência de qualquer religião, levando em conta o que está na Constituição do país.

\section{Referências}

AMOSSY, Ruth (org.). Imagens de si no discurso: a construção do ethos. São Paulo: Contexto, 2005.

CHARAUDEAU, Patrick. Discurso político. São Paulo: Contexto, 2013.

- Identidade social e identidade discursiva, o fundamento da competência comunicacional. In. PIETROLUONGO, Márcia (Org.). 0 trabalho da tradução. Rio de Janeiro: Contra Capa, 2009a. 
EID\&A - Revista Eletrônica de Estudos Integrados em Discurso e Argumentação, Ilhéus, n. 14, jul/dez.2017.

. La argumentación persuasiva. El ejemplo del discurso político. In. SHIRO M. \& ALII. Haciendo discurso. Homenaje a Adriana Bolívar. Caracas: Faculdad de Humanidades y Educación, Universidad Central de Venezuela, $2009 \mathrm{~b}$.

O que quer dizer comunicar. Mimeo. Rio de Janeiro: CIAD/Rio, 1994.

MAINGUENEAU, Dominique. Ethos, cenografia, incorporação. In. AMOSSY, Ruth (org.). Imagens de si no discurso: a construção do ethos. São Paulo: Contexto, 2005.

Jornal O Globo. Disponível em http://oglobo.globo.com/brasil/eduardo-cunha-sobreaborto-vai-ter-que-passar-por-cima-do-meu-cadaver-para-votar-15290079. Acesso em 06 nov. 2015. 
EID\&A - Revista Eletrônica de Estudos Integrados em Discurso e Argumentação, llhéus, n. 14, jul/dez.2017.

Anexo - Impressão de tela da notícia

Figura 1 - Notícia: Eduardo Cunha sobre o aborto: 'vai ter que passar por cima do meu cadáver para votar', no site do jornal O Globo

https://oglobo.globo.com/brasil/eduardo-cunha-sobre-aborto-vai-ter-que-passar-por-cima-do-meu-cadaver-para

B GLOBO $\equiv$ BASIL
que passar por cima do meu cadáver
para votar'

Presidente da Câmara foi eleito para o cargo com apoio da bancada evangélica

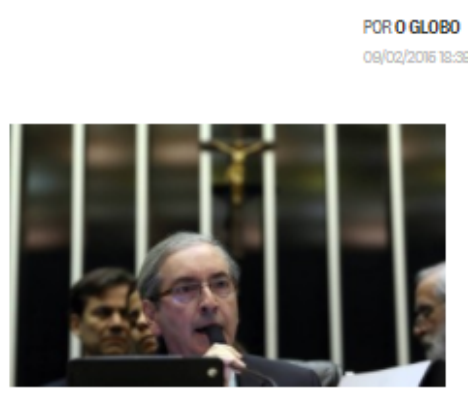

O presidente da Câmara, Eduardo Cunha (PMDBRJJ) - Givaldo Barbosa/5-2-2015 / Agência O Globo

BRASÍLIA - O presidente da Câmara, Eduardo Cunha (PMDB-RJ), reafirmou nesta segunda-feira ser "radicalmente contra" a votação de qualquer projeto de legalização do aborto no Brasil. Em entrevista ao site do jornal "Estado de S. Paulo", publicada hoje, Cunha foi taxativo: "Vai ter que passar por cima do meu cadáver para votar".

- Os projetos têm um rito, não é qualquer um que apresenta um projeto e vota. Quem aprova urgência com 257 votos, quem tem maioria, tem que pautar. Eu disse que sou radicalmente contrário e sou mesmo. Mas não tem nenhum projeto. $O$ pessoal fala como se tivesse algo na pauta, e eu estivesse tirando da pauta, mas não existe isso - disse Cunha.

O presidente da Câmara é evangélico e foi eleito para o cargo com apoio da bancada evangélica, inclusive de deputados de partidos da oposição que preferiram Cunha por sua orientação religiosa. 0 grupo exerce forte pressão para que matérias de amparo à saúde da mulher em caso de aborto e ampliação dos direitos dos homossexuais não sejam votadas no Congresso. No ano passado, a bancada conseguiu fazer com que o governo recuasse em uma portaria que previa procedimentos no SUS para os casos de aborto legal.

Cunha se reúne na tarde de hoje o presidente do Senado, Renan Calheiros (PMDB-AL), para definir a pauta de votações dos próximos dias. Antigos desafetos, os dois têm se aproximado desde que foram eleitos para comandar as duas Casas do Congresso para trabalharem afinados e manter postura de "independência" em relação ao Executivo.

Fonte: Jornal O Globo. Disponível em http://oglobo.globo.com/brasil/eduardo-cunhasobre-aborto-vai-ter-que-passar-por-cima-do-meu-cadaver-para-votar-15290079. 
EID\&A - Revista Eletrônica de Estudos Integrados em Discurso e Argumentação, llhéus, n. 14, jul/dez.2017.

Forma de citação sugerida:

DUARTE, Camilla Ramalho; MONNERAT, Rosane Santos Mauro. Só passando por cima do meu cadáver: uma análise do discurso de Eduardo Cunha sobre a legalização do aborto. EID\&A - Revista Eletrônica de Estudos Integrados em Discurso e Argumentação, Ilhéus, n. 14, p. 52-65, jul/dez.2017.

Recebido em: 20/09/2017

Aprovado em: 27/11/2017 